\title{
Analysis of mechanism of carbide tool wear and control by wear process
}

\author{
Hoang Trung Pham ${ }^{1, *}$, and Julius. L. Tchigirinsky ${ }^{1}$ \\ ${ }^{1}$ Volgograd State Technical University, 400005, 28 Lenin av., Volgograd, Russia
}

\begin{abstract}
The analysis of physic-mechanical and thermal physic properties of hard alloys depending on their chemical composition is conducted. The correlation of cutting properties and regularities of carbide tool wear with cutting conditions and thermal physic properties of tool material are disclosed. Significant influence on the tool wear of not only mechanical, but, in the first place, thermal physic properties of tool and structural materials is established by the researches of Russian scientists, because in the range of industrial used cutting speeds the cause of tool wear are diffusion processes. The directions of intensity decreasing of tool wear by determining rational processing conditions, the choice of tool materials and wear-resistant coating on tool surface are defined.
\end{abstract}

\section{Analysis of the mechanism of carbide tool wear}

Depending on the physical-mechanical properties of work and tool materials, the type of contact interaction, contact temperatures and contact stresses, the type of lubricant-cooling agents, their cooling effect, the possibility of lubricant-cooling agents penetration on the boundary surface of contact interaction and of chemical reactions passing there, as well as the possibility of diffusion processes passing through the boundary of work and tool materials, tool wear can have various physical nature and there may be various wear mechanisms.

The diversity of wear content and manifestations can be divided into two types: continuous dissolution at atomic level of worn material in the wearing; wear by removing discrete submicro- and micro-volumes from worn surface, having finite geometrical dimensions.

While cutting metals can take place following wear mechanisms: diffusion, adhesion-fatigue, oxidation, abrasive and wear as a result of cutting edge microspall [13]. The diffusion wear is most common of them, which can be described in the following way. Mutual diffusion of tool and work materials occurs while cutting in determination conditions of stable adhesion bond. During this process takes place, first, the carbides dissociation (mostly tungsten carbides) and subsequent diffusion of the elements $(\mathrm{W}, \mathrm{Ti}, \mathrm{C})$ in the work material (direct diffusion dissolution); second, metal elements diffusion of the work material in the binding phase of hard alloy and its softening. The consequence is bond weakening, holding carbide grains or groups of carbides in the hard alloy, tear-out and ablation by their border volumes of work material. The result of both processes is the wear of tool contact surfaces.
According to the views of N. V. Talantov [14], the type of contact interaction in a certain way has an influence on the mechanism and intensity of tool wear, as well as forming main characteristics of the cutting process. It is known that while cutting carbon and lowalloy ferrite-pearlite steels with increase in cutting speed there is regular change of the following types of contact interaction: build-up, throbbing contact zone, and zone of relative stagnation, plastic and viscous contact. For high-alloy steels with the increase in cutting speed process is characterized by the regular change, mainly of the same types of contact interaction, as for ferritepearlite steels: interaction in cutting with cleavage chips formation, the build-up, the cutting with plastic yielding of contact layers of the work material, in which there are no phenomena of their full stagnation [10].

While analyzing the cutting process differences of high-alloy steels from carbon and low-alloy steels often compare their thermal conductivity values at a fixed temperature. The thermal conductivity decreases with the increase in contact zone temperature during cutting carbon and low-alloy steels, and for high-alloy increases (Fig. 1) [10]. This is because while cutting carbon and low-alloy steels there is a positive feedback in temperature, i.e. increasing $\theta$ in the contact zone leads to a decreasing of heat flow into the chip due to reduction $\lambda$ and consequently to a further increase in $\theta$. Therefore, the transition with increase in cutting speed from built-up edge to the plastic yielding of contact layers is accomplished abruptly, in a narrow speeds range, and the appearance of this kind of interaction almost immediately is accompanied by the emergence of diffusion-viscous flow and crater wear. The opposite character of the dependence $\lambda(\theta)$ for austenitic and martensitic steels entails a negative feedback on the cutting temperature - with the increase in heat flow into the chip while temperature rising in the contact zone.

\footnotetext{
${ }^{*}$ Corresponding author: phamhoangtrung@mail.ru
} 
This leads to a contrast weakening in temperature along the length of the contact and contributes to the process development of secondary strain hardening in the contact zone at a distance from the cutting edge.

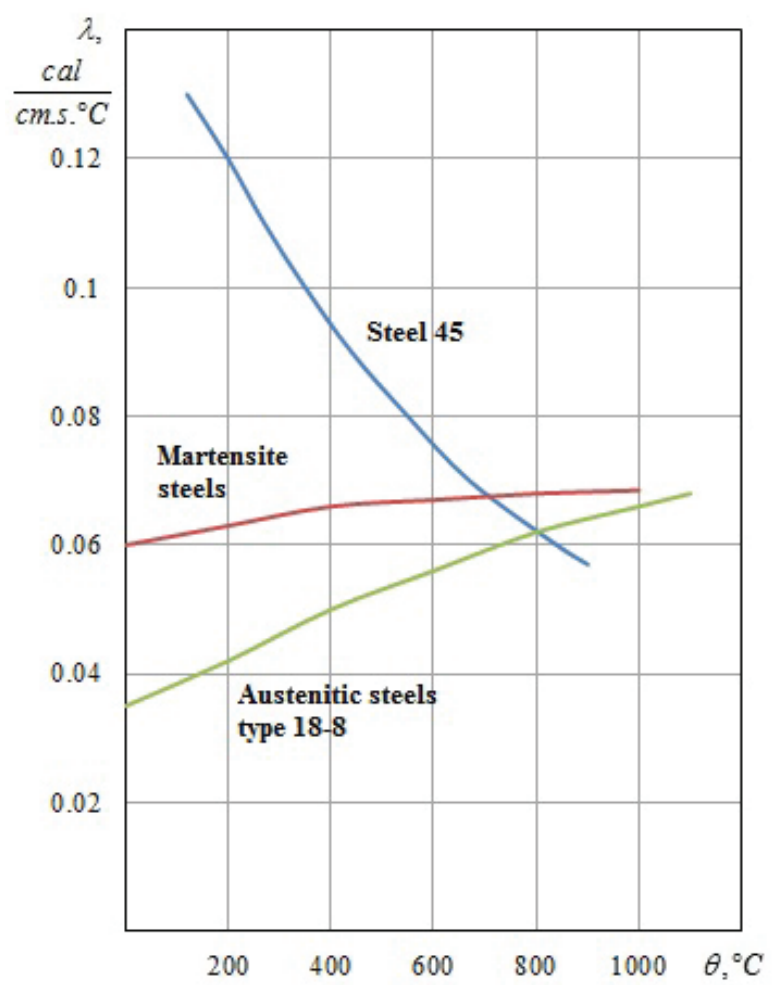

Fig. 1. The dependences of thermal conductivity coefficient of processing steels on temperature

There occurs the transition from built-up edge to a stagnant zone with an offset built-up while processing high-alloy steels with the increase in cutting speed. The main characteristic of this kind of interaction is the presence of fixed amounts of hardened metal at some distance from the cutting edge, calling the braking plastic yielding in the most part of the zone. The offset build-up is the result of secondary hardening of the contact layers of the work material.

The offset build-up disappears with further increasing of cutting speed and stagnant zone gives way to interaction with the plastic yielding of contact layers. However, the increasing of the heat flow into the chip with the increase in temperature prevents the deformation localization and the transition from plastic yielding of contact layers to viscous. Consequently the area of viscous contact (wear crater) is absent, and there is interaction with the plastic contact without viscous in a enough wide range of cutting speeds.

If when cutting ferrite-pearlite steels all kinds of interaction at the wear area on the back edge are offset relatively similar types on the front surface in the direction of high speeds, while processing high alloy steels this is not observed. For austenitic steel the transition to plastic yielding at the wear area is completed at lower cutting speeds than on the front surface. For martensitic steels the interaction with plastic contact is formed on the front surface and the wear area at close values of the cutting speed. This is due to the aforementioned differences of the thermal physic properties for these work material groups [10].

\section{Control by wear process}

Control by wear process of carbide tools can be implemented by determining the processing mode, the properties of tool and work material, and the features during processing and application on the working surface of the wear-resistant layer.

When establishing a stable adhesive bond between the work and tool materials along the actual tool surface, this is possible between these materials for the flow of two types of diffusions: heterogeneous and reactive. In the first case the solid solution is formed with the solvent lattice. In reactive diffusion at the boundary the chemical reaction can be to form intermetallic compounds or carbides. The formation condition of new phases during reactive diffusion is that substance participating in the process by its nature could form intermetallic compounds or carbides [13].

This can be observed when processing high alloy (titanium, cobalt) steels. The natural carbide coating is formed in the result of diffusion processes on the carbide tool surface under certain conditions. It consists of carbide-forming elements of steel and hard alloy elements. This process prevents the wear of hard alloy by the mechanism of the direct dissolution $[10,11]$.

In addition, there are series of processing technologies of working surfaces, giving them the additional hardening, the most effective of which is a method of applying to the cutting tool surface with special coatings of solid compounds.

By coating the working tool surface most effectively resists the typical types of tool wear. The most perspective innovative direction of the wear-resistant coatings modernization is the development of universal multilayer coatings, permitting in full degree to take into consideration of complex technological conditions of the cutting process.

The main reasons for the failure of tools with coatings are: the deformation of the wedge and the coatings diffusion wear. In this case in the capacity of matrixes under coating, we should choose a less plastic hard alloys. As coatings it is necessary to apply more wear-resistant compound [8]. Note that the application of coatings requires the absence of variable loads during processing.

At the level of the using additional technological operations when cutting hard-to-machine materials it is possible to apply advanced plastic deformation (APD). Machining with APD combines the advanced plastic deformation and subsequent cutting. By the beginning of the removal of the stock part work, which takes costs for cutter for plastic deformation already being performed by the device for the implementation of APD. This means that during machining with APD only part of work is implemented by implemented [8]. 

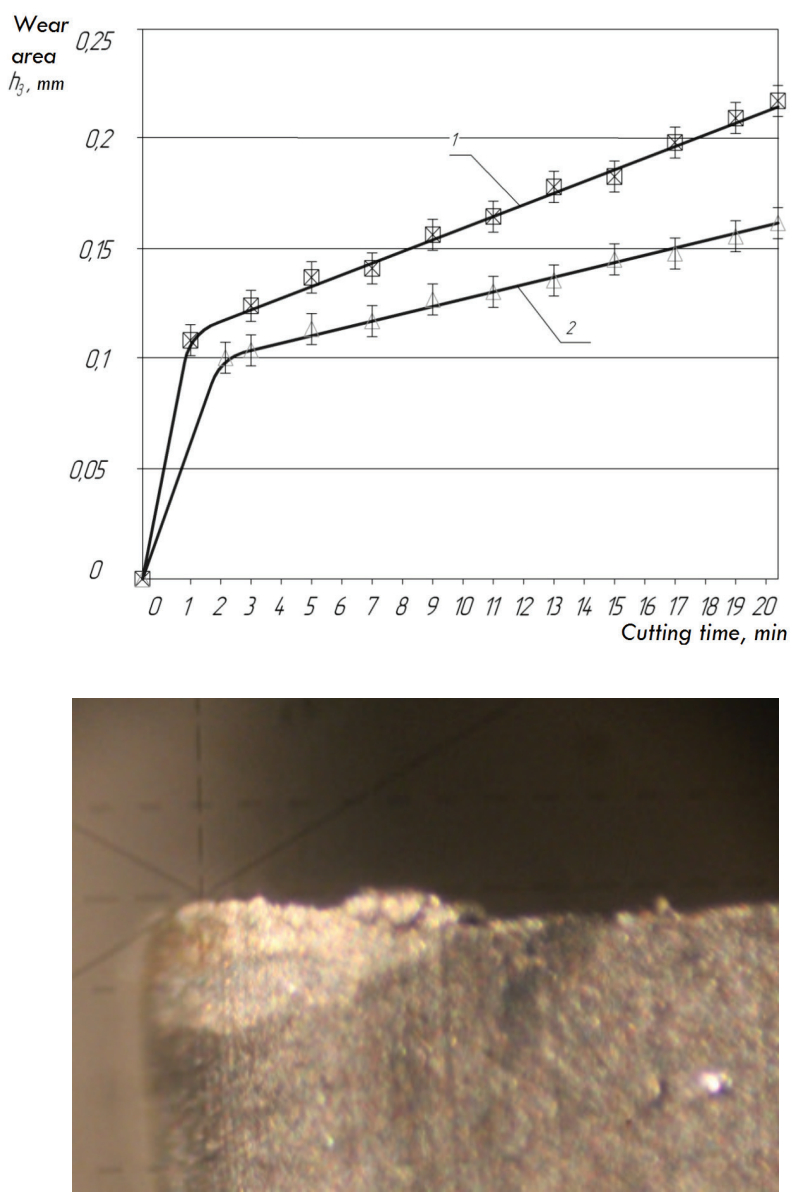

Turning

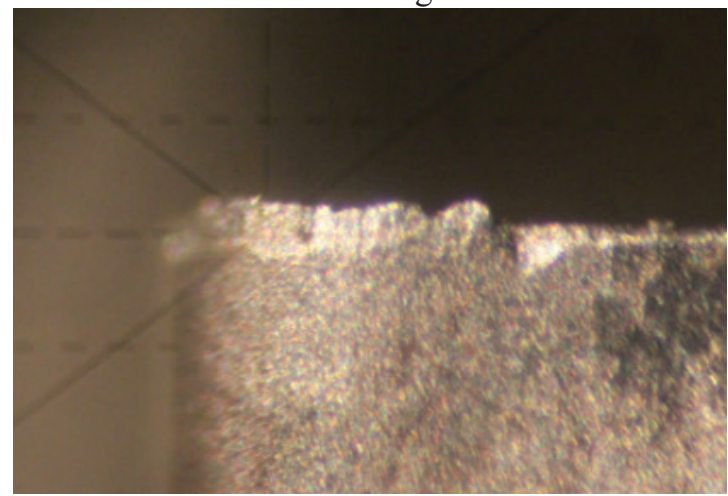

Turning with APD $\left(K_{A P D}=2\right)$

Fig. 2. The dependence of the area size of the flank wear of the cutter from cutting time.

Steel 30CrMo4 - hard alloy WC 79-TiC 15-Co 6; $t_{p}=1 \mathrm{~mm} ; v_{p}=90 \mathrm{~m} / \mathrm{min} ; \mathrm{s}_{o}=0,256 \mathrm{~mm} / \mathrm{rev}$. (According to the source [8])

Scientists of Volgograd State Technical University (Norchenko P. A., Krainev D. V., Bondarev A. A., Ingemansson A. R.) have conducted a series of experiments to study the process of the cutting tool wear in the machining of structural carbon and alloyed steels and compared the results with traditional turning and turning with APD. It is discovered that while turning with APD a substantial reduction of tool wear of cutting blades is achieved on the main flank, thereby the processing productivity and the resource of the tool workability are increased in comparison with the traditional machining (Fig. 2) [7,8].

The application of advanced plastic deformation leads to a decreasing in intensity of the tool wear by reducing the cutting forces and the intensity of diffusion penetration of iron atoms to the structure of the hard alloy. The tool resistance increases from 25 to $100 \%$.

After cutting with advanced plastic deformation the surface roughness is reduced sharply (in many cases from 2 to 4 times), which permits to shorten the number of technological transitions, as well as to improve surface micro profile (in particular, the length of the reference line is increased).

The specific recommendations on the appointment of cutting modes with advanced plastic deformation were formulated. As fundamental criteria for the appointment of cutting modes has been selected: the minimum relative surface wear and minimum roughness of the machined surface [7].

\section{References}

1. Classification of tool materials: [Electronic resource].- Access mode: http://studopedia.ru/4_17307_klassifikatsiyainstrumentalnih-materialov.html

2. Hard alloys. The brands of hard alloys. The application of hard alloys: [Electronic resource].Access mode : http://yaruse.ru/posts/show/id/949

3. N. C. Gerasimova, N. N. Gerasimov. Tool materials: tutorial (Mos. state technical university named N. E. Bauman. - M.: Kaluga, 2016)

4. N. N. Zubkov, Tool materials for the manufacture of cutting tools (Scientific edition of the Bauman MSTU named N. E. Bauman. - M.: Science and education, 2013)

5. Ju. S. Sharyn, T. I. Tishenina. Handbook turner (Environments Ural book publishing house: Sverdlovsk, 1985)

6. The system of "Industrial catalogues" / Industrial catalogs // Lab2U: [Electronic resource]. - Access mode: http://lab2u.ru.

7. P. A. Norchenko, Increasing the efficiency of the cutting process of stainless steels of austenitic class with advanced plastic deformation: diss. cand. tech. sciences: 05.02.07. (Volgograd, 2010)

8. A. A. Bondarev, Study of the influence of advanced plastic deformation on the efficiency of the cutting process of structural steels: diss. cand. tech. sciences: 05.02.07. (Volgograd, 2016)

9. Ju. M. Bikov, Investigation of the regularities of carbide tool wear with wear-resistant coatings for the purpose of increasing its workability: diss. cand. tech. sciences: 05.03.01. (Volgograd, 1983)

10. A. A. Lipatov, Regularities of the cutting process high alloy steels and the ways to improve the workability of carbide tool: diss. cand. tech. sciences: 05.03.01. (Volgograd, 1987) 
11. Ju. L. Tchigirinsky, Pham Hoang Trung, A. A. Lipatov, Features of Processing of Corrosion Resistant Steels, MSF, Vol. 870, pp. 598-602 (2016) - DOI 10.4028/www.scientific.net/MSF.870.598

12. N. V. Talantov, Mechanism of carbide tool wear when machining steels, Bulletin of mechanical engineering, N 7, pp. 52-57 (1985)

13. N. V. Talantov, Physical basis of the cutting process, the tool wear and the tool destruction (M.: Mechanical Engineering, 1992)

14. N. V. Talantov, Physical basis of cutting process, Physical processes in the cutting metals: collection of articles, Volgograd: VPI, 3-37 (1984)

15. N. V. Talantov, Physical basis of the cutting process and the tool wear: tutorial. (Volgograd: Volgograd truth, 1987)

16. A. S. Vereshchaka, I. P. Tretyakov. Cutting tools with wear-resistant coatings (M.: Mechanical Engineering, 1986) 